\title{
Regulation on introducing process of the highly difficult new medical technologies: A survey on the current status of practice guidelines in Japan and overseas
}

\author{
Kazuo Minamikawa ${ }^{1,2,3}$, Akiko Okumura ${ }^{3,4}$, Norihiro Kokudo ${ }^{3,5}$, Koji Kono ${ }^{1,3, *}$ \\ 'Departments of Gastrointestinal Tract Surgery, Fukushima Medical University, Fukushima, Japan; \\ ${ }^{2}$ Medical Research Center, Fukushima Medical University, Fukushima, Japan; \\ ${ }^{3}$ Special Research Group on Evaluation and Improvement of Clinical Guidelines for Introduction Process of Highly Difficult New \\ Medical Technologies, Japan; \\ ${ }^{4}$ Department of EBM and Guidelines, Japan Council for Quality Health Care, Tokyo, Japan; \\ ${ }^{5}$ Department of Surgery, University of Tokyo, Tokyo, Japan.
}

\begin{abstract}
Summary Since serious problematic cases regarding the technical safety of technically demanding operations were reported in Japan, the Ministry of Health, Labor and Welfare issued new regulations on June 10, 2016 requiring each hospital to check the status of informed consent, skill of surgery team and governance system of the surgical unit, when the highly difficult new medical technologies were introduced to a hospital. In order to firmly establish this new system for highly difficult new medical technologies, it is very important and informative to survey the current situation for guidelines and consensus regarding introduction of medical technology with special skills in Japan and overseas. Based on the survey of questionnaires, document retrieval, and expert interviews, we found that documentation related to the introduction process of highly difficult medical technologies is very rare, and the regulations were mainly issued by academic societies. Moreover, even if such documentation existed, the quality of the regulations is poor and not sufficient enough to perform surgical practice safely. Therefore, for medical practitioners, comprehensive and concrete regulations should be issued by the government or ministry to legally follow in regard to technically demanding operations. A new practice guideline was proposed by our special research group to regulate the introduction process of highly difficult new medical technologies in hospitals in Japan. This guideline, gained understanding from relevant academic societies, provided a comprehensive view on the interpretation of "high difficulty new medical technology" prescribed by the law and show the basic idea at a preliminary examination from the viewpoints of "Surgeon's requirement", "Guidance system", "Medical safety" , and "Informed consent". These efforts will contribute to the improvement of the quality of guidelines regarding "highly difficult new medical technology".
\end{abstract}

Keywords: Technically demanding operation, guidelines, technical safety, medical safety

\section{Introduction}

There have been great advances in surgical techniques

Released online in J-STAGE as advance publication December 28,2018 .

*Address correspondence to:

Dr. Koji Kono, Departments of Gastrointestinal Tract Surgery, Fukushima Medical University, 1 Hikarigaoka, Fukushima, Fukushima 960-1295, Japan.

E-mail:kojikono@fmu.ac.jp resulting in improved quality of life (QOL) and better overall survival in several types of operations, including laparoscopic and thoracoscopic approaches $(1,2)$. However, in 2014, serious problematic cases in technical safety for technically demanding operations such as laparoscopic liver resection and laparoscopic pancreatic resection were reported one after another in Japan, in hospitals such as university hospitals, which provide advanced medical care $(3,4)$.

On June 10, 2016, the Japanese Ministry of Health, Labor and Welfare revised the ministerial ordinance for 


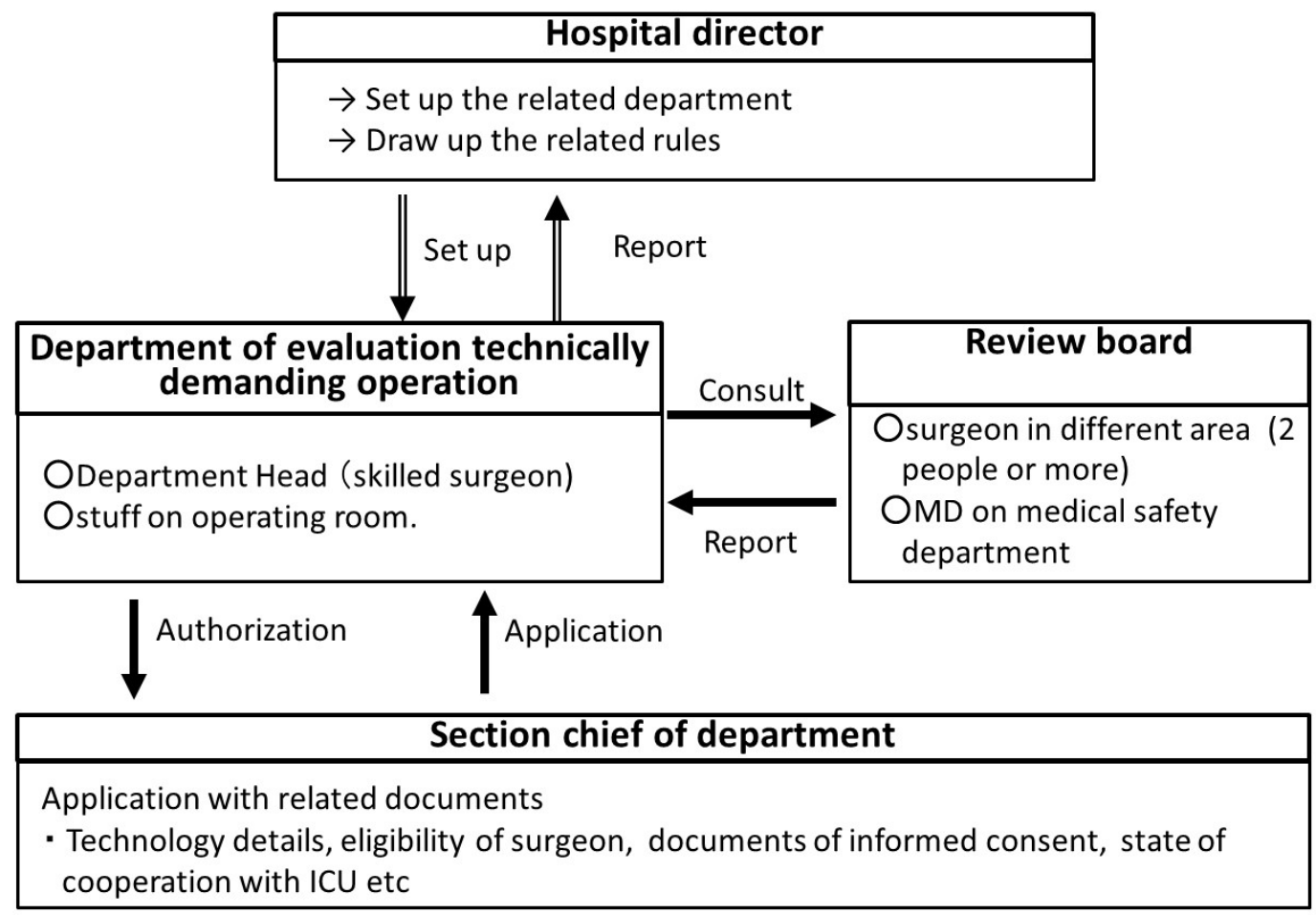

Figure 1. Framework of regulations when newly introducing a technically demanding operation imposed by medical care act. This regulation was enforced on the 10 of June in 2016. Special Functioning Hospitals are obligated, and other hospitals are obligated to make a sincere effort.

the Medical Service Law (5), and decided to impose certain procedures or regulations on each hospital in Japan, requiring them to check the status of informed consent, skill of surgery team and governance system of the surgical unit, when medical practitioners are going to introduce highly difficult new medical technologies that severely effects patients (Figure 1) (6).

In addition, in order to firmly establish this new system for the introducing process of highly difficult medical technologies, the Ministry of Health, Labor and Welfare organized a Special Research Group on Evaluation and Improvement of Clinical Guidelines Concerning Introducing Process of Highly Difficult New Medical Technologies (hereinafter referred to as "special research group"), where they, together with related academic societies, tried to survey the current situation for guidelines and consensus regarding introducing processes of highly difficult new medical technologies in Japan and overseas (7).

In this study, we present the research findings on current status of such clinical guidelines in Japan and overseas, via survey of questionnaires, document retrieval, and expert interviews. Furthermore, with reference to the survey results, we proposed a new practice guideline to regulate the introduction process of highly difficult new medical technologies in each hospital in Japan.

\section{Materials and Methods}

\subsection{Survey of the guidelines in Japan}

A questionnaire survey conducted between August 12 and September 28, 2016 for the documents related to the introduction process of the highly difficult new medical technologies were sent to the 18 academic societies (Table 1) belonging to the Japanese Medical Specialty Board. Based on the inquires, we received a response from all 18 academic societies, and 38 related documents were gathered. After second-round selection, 32 published documents were assigned to this study for further analysis. Especially, among these documents, we investigated the presence/absence of descriptions of "surgeon's requirement", "guidance system for the introduction", "medical safety related to facility standards" and "informed consent".

\subsection{Survey of the guidelines overseas}

From the information published at the National Guideline Clearinghouse (NGC, issued from 2004 to 2016) operated by the Agency for Healthcare Research and Quality (AHRQ, USA) and the National Institute for Health and Care Excellence (NICE, UK), literature surveys were conducted in July 2016 regarding the presence or absence of overseas clinical practice guidelines related to surgery and procedures. The retrieval keywords included "technology appraisal guidance", "medical technologies guidance", "surgeon credentialing", "training guidelines", "privileging qualified surgeons", "minimal requirements for granting privileging surgeons", and "technically demanding surgery". 
Table 1. Survey on the documents related to introduction process of the highly difficult new medical technologies in 18 academic societies in Japan

\begin{tabular}{|c|c|c|c|c|}
\hline \multirow[b]{2}{*}{ Title of documents } & & \multicolumn{3}{|c|}{ Contents } \\
\hline & Organization & $\begin{array}{c}\text { Surgeon's } \\
\text { requirement }\end{array}$ & $\begin{array}{c}\text { Guidance } \\
\text { system }\end{array}$ & $\begin{array}{c}\text { Medical Informed } \\
\text { safety consent }\end{array}$ \\
\hline
\end{tabular}

- Guidelines for endoscopic surgical procedures

Japan Society for Endoscope Surgery requirement system safety consent

- Recommendations on introducing endoscopic

surgery assisted robotic surgery

- Consensus for introduction of new medical devices

- Compliance with the conditions for introducing robot-assisted endoscopic surgery

- Proper usage guidelines for percutaneous transluminal cerebral thrombus collection device

- Proper usage guidelines for intracranial artery stent

(for arteriosclerosis)

- Intracranial artery stent (Flow Diverter for treatment

of cerebral aneurysm) Proper usage guidelines

- Requirements such as system for appropriate use of cranial nerve area medical devices

- Transcatheteric aortic valve replacement surgery implementation facility standard

- Institutional criteria for use of human skeletal muscle derived cell sheets and practicing medical standards

- Implantable assistant artificial heart certification facility $\cdot$ Physician update standard

- Certification Criteria for Heart Transplant Implementation Facilities

- Criteria for thoracic aortic aneurysm stent graft implementation

- Call attention to academic society members

The Japan Stroe Society, the Japan Neurosurgical Society, the Japanese Society for NeuroEndovascular Therapy

The Japan Society for Endoscopic Surgery, The Japan Neurosurgical Society, Japanese Society of Interventional Radiology

Council for Transcatheteric Aortic Valve Replacement Surgery Related Association

Human Skeletal Muscle Derived Cell Sheet Related Academic Conference

Association for Assistive Cardiac Therapy

Council for Heart Transplant Association

Japan Stent Graft Implementation Standards Management Committee

Japan Society for Endoscope Surgery, Japanese Society of Hepato-BiliaryPancreatic Surgery, The Japanese Society of Gastroenterological Surgery, Japan Surgical Society

- Implementation guidelines for vagal nerve stimulation therapy for epilepsy

- Guidelines on indication for epilepsy surgery

- Guidelines on the diagnosis of internal medial

temporal lobe epilepsy and surgical adaptation

- Surgical treatment guidelines for neocortica epilepsy

- Brain tumor clinical practice guidelines

- Brain tumor clinical practice guideline: centra nervous system primary malignant lymphoma

- Urological laparoscopic surgery guideline 2014 edition

- Guidelines for conducting da Vinci assisted surgery in the field of urology

- Guidelines on robot-assisted surgery for gynecological malignancies

- Guidelines on robot-assisted surgery for gynecological malignancies

- Cataract surgery Combined intraocular drain requirement criteria

- Guidelines for refractive surgery

- Lens Expansion Ring Usage Guidelines

- Endoscopic surgical guidelines for obstetrics and gynecology

- Guidelines for Certification System for Awakening Brain Surgery Facilities

- Guidelines for Acute Blood Purification Therapy for Neonates by Extracorporeal Circulation

- Adaptation guidelines for catheter treatment for congenital and childhood onset heart disease

- Congenital heart disease, Guidelines for catheter reatment for structural heart disease of cardiovascular

vessels (structural heart disease)

The Japan Society for Neuro-Oncology

\section{Japanese Society of Endourology}

The Japanese Urological Association, Japanese Society of Endourology

Japan Society of Obstetrics and Gynecology

Japanese Ophthalmological Society

Japan Society of Obstetrics and Gynecology

The Japan Neurosurgical Society

Japan Pediatric Society

Japan Epilepsy Society

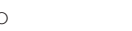


NICE and NGC were main databases of trustworthy clinical practice guidelines. NICE has integrated the systematic methods of clinical practice guidelines development, and NGC has adopted criteria for inclusion of clinical practice guidelines in NGC $(\rightarrow 2013$ (Revised) Criteria for Inclusion of Clinical Practice Guidelines in NGC).

\subsection{Expert interview for in-depth discussion}

We also interviewed two surgical professors, a gastrointestinal surgeon and a cardiac surgeon at the National University of Singapore, about the process of introducing highly difficult new medical technologies in Singapore, and discussed the current situation in Western and Asia-Pacific countries.

\section{Results}

\subsection{Survey of the guidelines in Japan}

We examined the contents of 32 published documents released by 18 academic societies belonging to the Japanese Medical Specialty Board out of 38 related documents gathered as a result of the survey in Japan. Among the 32 documents, 22 included at least one of the following items: surgeon's requirement (22 documents, 68.8\%); guidance system (11 documents, $34.4 \%$ ); medical safety matters (13 documents, 40.6\%), and informed consent (10 documents, 31.3\%). These descriptions were described as the general parts of the guidelines, or were commented on as the question and answer (Q \& A) system. These documents belonged to guidelines ( 9 documents, $28.1 \%$ ), guidance (4 documents, $12.5 \%$ ) and other categories. A list of the documents is shown in Table 1.

\subsection{Survey of the guidelines overseas}

We surveyed the website of the NGC (issued from 2004 to 2016) operated by the AHRQ (https://www.guideline. gov) as the category of "Surgery" and 390 guidelines were selected. Among them, 75 were further selected (published in 2011-2016) after a quality control based on whether the guidelines matched the criteria for NGC publication was performed (8). A list of these documents is shown in Table 2. Although two of the 75 documents were listed through a title search for corresponding documents, we found no descriptions regarding clinical practice guidelines when newly introducing highly difficult new medical technologies $(9,10)$.

On the NICE website (https://www.nice.org.uk/ guidance), we searched the category of "Technology appraisal guidance" and "Medical technologies guidance". We found 188 cases and 28 cases, respectively (issued between 2011 and 2016). However, after conducting a title search for these cases, there were no documents describing the introduction of the highly difficult new medical technologies.

Also on the NICE website, we searched for keywords such as "surgeon credentialing", "training guidelines", "privileging qualified surgeons", "minimal requirements for granting privileging surgeons", and "technically demanding surgery", and as a result, eight documents were selected. After an extensive evaluation of the contents, two documents were matched, "Laparoscopic repair of abdominal aortic aneurysm" and "Laparoscopic retroperitoneal lymph node dissection for testicular cancer" $(11,12)$ (Table 3). Both documents included guidance for "informed consent that the procedure is technically difficult", "registering the procedure in a database", and "performing the procedure with a multidisciplinary team", although the contents are simple and thin with only one page.

\subsection{Expert interview for in-depth discussion}

As a result of the interview survey with the surgeons from the National University of Singapore, there is no unified rule in Singapore regulated by the government, and there is a unique arrangement in the National University of Singapore Hospital that a preliminary review is carried out when newly introducing technically demanding operations. In addition, as clinical practice for robotic surgery in Singapore, "A consensus document on robotic surgery" (13) is routinely used. This document was prepared by a consensus group consisting of academic organizations in the United States, and contained necessary and sufficient conditions for technically demanding operations, in which detailed descriptions regarding surgeon's requirements, guidance system for the introduction, and medical safety related to the facility standards are included (Table 4).

\subsection{The new practice guideline proposed in Japan to regulate the introducing process of highly difficult new medical technologies in the hospital}

With reference to the survey of questionnaire and document retrieval, our special research group proposed a new practice guideline to regulate the introducing process of highly difficult new medical technologies in each hospital in Japan (14), which are controlled by the ministerial ordinance for the Medical Service Law (Table 5). This guideline provided a comprehensive view on the interpretation of "high difficulty new medical technology" prescribed by the law so that the medical institution can properly understand or judge. In addition, we show the basic idea at preliminary examination from the viewpoints of "Surgeon's requirement ", "Guidance system", "Medical safety", and "Informed consent". 
Table 2. Survey of national guidelines overseas from NGC operated by the AHRQ published from 2011 to 2016

Published Year Title of clinical practice guidelines

2016 - Practice guidelines for the prevention, detection, and management of respiratory depression associated with neuraxial opioid administration: an updated report by the American Society of Anesthesiologists Task Force on Neuraxial Opioids and the American Society of Regional Anesthesia and Pain Medicine.

- Guideline for prevention of retained surgical items.

- Guideline for care of the patient receiving moderate sedation/analgesia.

- Blood transfusion.

- Guideline for prevention of unplanned patient hypothermia

- Prophylaxis against infective endocarditis: antimicrobial prophylaxis against infective endocarditis in adults and children undergoing interventional

- procedures.

- Treatment of Cushing's syndrome: an Endocrine Society clinical practice guideline.

- Everolimus for preventing organ rejection in liver transplantation.

- Merkel cell carcinoma.

- Lower urinary tract symptoms in men: assessment and management

- Venous thromboembolism in adults admitted to hospital: reducing the risk.

- Society for Vascular Surgery practice guidelines for atherosclerotic occlusive disease of the lower extremities: management of asymptomatic

- disease and claudication.

- Bladder cancer: diagnosis and management.

- Platelet transfusion: a clinical practice guideline from the AABB.

- Practice guidelines for perioperative blood management: an updated report by the American Society of Anesthesiologists Task Force on

- Perioperative Blood Management.

- Gastro-oesophageal reflux disease: recognition, diagnosis and management in children and young people.

- Peyronie's disease: AUA guideline.

- ACR Appropriateness Criteria ${ }^{\mathbb{B}}$ radiologic management of hepatic malignancy.

- American Geriatrics Society abstracted clinical practice guideline for postoperative delirium in older adults.

- ACR Appropriateness Criteria ${ }^{\circledR}$ routine chest radiography.

2014 - Guideline for autologous tissue management.

- Intrapartum care: care of healthy women and their babies during childbirth.

- Acromegaly: an Endocrine Society clinical practice guideline.

- Guideline for preoperative patient skin antisepsis.

- Optimal systemic therapy for early female breast cancer.

- Locoregional therapy of locally advanced breast cancer (LABC).

- Dyspepsia and gastro-oesophageal reflux disease. Investigation and management of dyspepsia, symptoms suggestive of gastro-oesophageal reflux

- disease, or both.

- Drug allergy: diagnosis and management of drug allergy in adults, children and young people.

- Management of venous leg ulcers: clinical practice guidelines of the Society for Vascular Surgery and the American Venous Forum.

- Systemic therapy for patients with advanced human epidermal growth factor receptor 2-positive breast cancer: American Society of Clinical

- Oncology clinical practice guideline.

- $2013 \mathrm{AHA} / \mathrm{ACC} / \mathrm{TOS}$ guideline for the management of overweight and obesity in adults: a report of the American College of Cardiology/American Heart Association Task Force on Practice Guidelines and The Obesity Society.

- Pheochromocytoma and paraganglioma: an Endocrine Society clinical practice guideline.

- Guidelines for laparoscopic peritoneal dialysis access surgery.

- Management of primary cutaneous squamous cell carcinoma. A national clinical guideline.

- Timing and type of surgical treatment of Clostridium difficile-associated disease: a practice management guideline from the Eastern Association

- for the Surgery of Trauma.

- Sentinel lymph node biopsy for patients with early-stage breast cancer: American Society of Clinical Oncology clinical practice guideline update.

- Clinical practice guideline on diagnosis and treatment of hyponatraemia.

- Pressure ulcers: prevention and management of pressure ulcers.

- Medical management of kidney stones: AUA guideline.

- Cervical spine injury medical treatment guidelines.

- Low back pain medical treatment guidelines.

- Total hip replacement and resurfacing arthroplasty for end-stage arthritis of the hip (review of technology appraisal guidance 2 and 44 ).

- Guideline for care of the patient receiving local anesthesia.

- Interventions for prevention and treatment of pressure ulcers. In: Prevention and treatment of pressure ulcers: clinical practice guideline.

- Adult weight management evidence-based nutrition practice guideline

- VA/DoD clinical practice guideline for the management of upper extremity amputation rehabilitation.

- ACR Appropriateness Criteria ${ }^{\mathbb{B}}$ aggressive nonmelanomatous skin cancer of the head and neck.

- ACR Appropriateness Criteria ${ }^{\mathbb{B}}$ blunt chest trauma - suspected aortic injury.

- Treatment of pressure ulcers. In: Prevention and treatment of pressure ulcers: clinical practice guideline.

- Blood transfusion in the management of sickle cell disease. In: Evidence-based management of sickle cell disease.

- ACR Appropriateness Criteria ${ }^{\circledR}$ radiologic management of lower gastrointestinal tract bleeding

- Special populations. In: Prevention and treatment of pressure ulcers: clinical practice guideline.

- ACR Appropriateness Criteria ${ }^{\circledR}$ resectable stomach cancer.

- Guideline for surgical attire.

- Managing acute complications of sickle cell disease. In: Evidence-based management of sickle cell disease.

- ACR Appropriateness Criteria ${ }^{\mathbb{B}}$ radiologic management of infected fluid collections.

- ACR Appropriateness Criteria ${ }^{\circledR}$ ductal carcinoma in situ.

- Guideline for management of wounds in patients with lower-extremity arterial disease.

- VA/DoD clinical practice guideline for screening and management of overweight and obesity

AHRQ, Agency for Healthcare Research and Quality; NGC, National Guideline Clearinghouse. 
Table 2. Survey of national guidelines overseas from NGC operated by the AHRQ published from 2011 to 2016 (Continued)

\begin{tabular}{|c|c|}
\hline Published Year & Title of clinical practice guidelines \\
\hline 2013 & $\begin{array}{l}\text { - Management of obstructive sleep apnea in adults: a clinical practice guideline from the American College of Physicians. } \\
\text { - Intraoperative tests (RD-100i OSNA system and Metasin test) for detecting sentinel lymph node metastases in breast } \\
\text { cancer. } \\
\text { - Summary of evidence-based guideline: periprocedural management of antithrombotic medications in patients with } \\
\text { ischemic cerebrovascular disease. Report of the Guideline Development Subcommittee of the American Academy of } \\
\text { Neurology. } \\
\text { - Clinical practice guideline on the management of invasive meningococcal disease. } \\
\text { - Clinical practice guidelines for the management of overweight and obesity in adults, adolescents and children in Australia. } \\
\text { - Clinical practice guidelines for the management of rotator cuff syndrome in the workplace. }\end{array}$ \\
\hline 2012 & $\begin{array}{l}\text { - Depth of anaesthesia monitors - Bispectral Index (BIS), E-Entropy and Narcotrend-Compact M. } \\
\text { - SonoVue (sulphur hexafluoride microbubbles) - contrast agent for contrast-enhanced ultrasound imaging of the liver. } \\
\text { - Red blood cell transfusion: a clinical practice guideline from the AABB. } \\
\text { - Early thrombus removal strategies for acute deep venous thrombosis: clinical practice guidelines for the Society for } \\
\text { Vascular Surgery and the } \\
\text { - American Venous Forum. } \\
\text { - Patient blood management guidelines: module } 4 \text { - critical care. } \\
\text { - Patient blood management guidelines: module } 2 \text { - perioperative. }\end{array}$ \\
\hline 2011 & $\begin{array}{l}\text { - Updated Society for Vascular Surgery guidelines for management of extracranial carotid disease. } \\
\text { for Vascular Surgery and } \\
\text { - the American Venous Forum. } \\
\text { - Patient blood management guidelines: module } 1 \text { - critical bleeding/massive transfusion. } \\
\text { - Guideline for processing flexible endoscopes. }\end{array}$ \\
\hline
\end{tabular}

AHRQ, Agency for Healthcare Research and Quality; NGC, National Guideline Clearinghouse.

Table 3. Survey of national guidelines overseas from NICE

\begin{tabular}{|c|c|c|c|c|c|}
\hline \multirow[b]{2}{*}{ Title of documents } & \multirow[b]{2}{*}{ Organization } & \multicolumn{4}{|c|}{ Contents } \\
\hline & & $\begin{array}{l}\text { Surgeon's } \\
\text { requirement }\end{array}$ & $\begin{array}{c}\text { Guidance } \\
\text { system }\end{array}$ & $\begin{array}{l}\text { Medical } \\
\text { safety }\end{array}$ & $\begin{array}{l}\text { Informed } \\
\text { consent }\end{array}$ \\
\hline $\begin{array}{l}\text { - Laparoscopic retroperitoneal lymph node dissection } \\
\text { for testicular cancer }\end{array}$ & $\begin{array}{l}\text { National Institute for Health and Care } \\
\text { Excellence }\end{array}$ & $\circ$ & & $\circ$ & $\circ$ \\
\hline - Laparoscopic repair of abdominal aortic aneurysm & & ० & & $\circ$ & ० \\
\hline
\end{tabular}

NICE, National Institute for Health and Care Excellence.

\section{Discussion}

In Japan, medical safety incidents in medical institutions that are well-equipped with medical facilities and human resources happen one after another when introducing high difficulty medical technology, and these incidents have become a social problem in 2016. Difficulty of hospital governance especially regarding the high level of expertise in surgery and procedures has been pointed out as the cause of these incidents. Therefore, it is an effective approach for the government to impose certain procedures from the viewpoint of securing medical safety for hospitals providing advanced medical care on the process of introducing "high difficulty new medical technology" and to establish cooperative relationships between government and hospitals and relevant academic societies by law.

The results of the present report indicate that before June 2016, there were no rules or guidelines regarding the introducing process of highly difficult new medical technologies at the governmental or ministerial levels in Japan and/or overseas.

Through our survey of document retrieval from Japan, we found that there are several documents specific to certain diseases or surgical procedures that describe the surgeon's requirements, a governance system for the surgical team, and other medical safety matters such as informed consent, and that the rules are organized by academic bodies or special committees, with the rules published as recommendations or guidance for the members of academic societies (Table 1). Thus, since these documents are recommendations or guidance, medical practitioners are not legally obliged to follow them.

Through the overseas survey, we were only able to find two simple regulations for laparoscopic surgery $(11,12)$ and one comprehensive guidance for robotic surgery (A consensus document on robotic surgery) (13). The robotic surgery guidance was made by a consensus group consisting of academic organizations, and had detailed descriptions of the surgeon's requirements, guidance system for introducing the procedure, and medical safety related to the facility standards (Table 4). However, these documents are also recommendations and guidance, and there are no rules issued at governmental or ministerial levels that legally have to be followed.

The results of our survey confirm that documentation related to the introduction process of highly difficult new 
Table 4. Description about "surgeon's requirement", "guidance system for the introduction", "medical safety related to the facility standards" on "A consensus document on robotic surgery, Appendix I: Guidelines for Institutions Granting Privileges in Therapeutic Robotic Procedures"

\begin{tabular}{|c|c|}
\hline Contents & Description \\
\hline $\begin{array}{l}\text { Surgeon's } \\
\text { requirement }\end{array}$ & $\begin{array}{l}\text { II. Minimum Requirements for Granting Privileges Part } \\
\text { A. Formal Specialty Training } \\
\text { Prerequisite training must include satisfactory completion of an accredited surgical residency program, with subsequent } \\
\text { certification by the applicable specialty board or an equivalent as required by the institution. } \\
\text { D. Practical Experience } \\
\text { 1. Applicant's Experience - Documented experience that includes an appropriate volume of cases with satisfactory } \\
\text { outcomes, equivalent to the procedure in question in terms of complexity. The chief of service should determine the } \\
\text { appropriateness of this experience. }\end{array}$ \\
\hline
\end{tabular}

Guidance system for the introduction

Medical safety related to the facility standards

II. Minimum Requirements for Granting Privileges Part

D. Practical Experience

1. Initial clinical experience on the specific procedure must be undertaken under the review of an expert and may include assisting. An adequate number of cases to allow proficient completion of the procedure should be performed with this expert review

IV. Maintenance of Privileges

C. Continuing Medical Education Continuing medical education related to the field should be required as part of the periodic renewal of privileges. Attendance at appropriate local, national or international meetings and courses is encouraged.

I. Principles of Privileging

C. Responsibility for Privileging

The privileging structure and process remain the responsibility of the institution at which privileges are being sought. It should be the responsibility of the specialty department, through its chief to recommend privileges for individual surgeons to perform procedures. These recommendations should then be approved by the appropriate institutional committee, board, or governing body.

III. Institutional Support

It is necessary that the staff and technical support team undergo a similar formal technical training with the device before its use in a clinical scenario. Therapeutic robotic surgery requires technical support and must be approached with a team concept.

IV. Maintenance of Privileges

A. Provisional Privileges

Once competence has been determined, a period of provisional privileges may be appropriate. The time frame and/or number of cases during this period should be determined by the chief of service and/or the appropriate institutional committee, board, or governing body.

B. Monitoring of Performance

Once privileges have been granted, performance should be monitored through existing quality assurance mechanisms at the institution. These mechanisms may be modified as appropriate, and should evaluate outcomes, as well as competency in the complete patient care process.

E. Denial of Privileges

Institutions denying, withdrawing, or restricting privileges should have an appropriate mechanism for appeal in place. The procedural details of this should be developed by the institution, and must satisfy the institution's bylaws and institutional recommendations

medical technologies is very rare, and the regulations that we found were mainly issued by academic societies. Moreover, even if such documentation existed, the quality of the regulations is poor and not enough to perform surgical practice safely. Therefore, for medical practitioners, comprehensive and concrete regulations should be issued by the government or ministry to follow legally with regard to technically demanding operations. With exceptional cases in the drug development and organ transplantation fields, there are several rules that have been issued by academic societies that are supported by law, such as the Pharmaceuticals and Medical Devices Act, and the Organ Transplant Act".

Before June 2016, there had been no consensus or rules for the introduction process for the technically demanding surgical procedures, and the process basically relies on the surgeon's decision or institutional common sense. However, these situations may cause a risk for patients with serious complications due to poor surgical technique and, in Japan, there have been reported problematic cases regarding technical safety for technically demanding operations such as laparoscopic liver resection and laparoscopic pancreatic resection. Therefore, for the Japanese Ministry of Health, Labor and Welfare to impose a certain procedure or regulations for a newly introducing process of a technically demanding operation is a very meaningful, impactful and innovative approach, from a medical safety point of view. Based on the new rules in Japan, each hospital needs to check the status of informed consent, skill of the surgery team, and governance system of the surgical unit, when medical practitioners are going to introduce highly difficult medical technology or technically demanding operation, each step of which is followed by an audit, evaluating and reporting system.

Furthermore, in introducing regulations to areas with high specialization, a special research group was established composed of experts before the system was enforced. This special research group, with the cooperation of the Japan Medical Society, proposed a new practice guideline which showed a comprehensive idea on preliminary review conducted at the hospital in introducing highly difficult new medical technology. This guideline is made with reference to relevant descriptions 
Table 5. Basic approach for the introduction of highly difficult new medical technologies in each hospital of Japan proposed by our special research group

\begin{tabular}{ll}
\hline Criteria & Contents \\
\hline Criteria "highly difficult" for & $\begin{array}{l}\text { It is stipulated by laws and regulations that "high difficult" means that the death or other serious effects of the } \\
\text { phighly difficult new difficult }\end{array}$ \\
patient will be assumed by the implementation for the hospital due to the high level of technical difficulty of
\end{tabular}
medical technologies" the medical technology.

We showed our views, other serious effects includes "Permanent or prominent Failure or malfunction".

We also showed our views, when each hospital judges the suitability of "high difficulty", the list that comprehensively grasp the technical difficulty level of surgical operations and procedures performed in Japan in cooperation with related academic societies in relation to the public insurance system, will be helpful for Medical institutions. In addition Medical technologies that are not widely disseminated should be judged individually and carefully at individual medical institutions for their suitability.

Criteria "new" for "highly It is stipulated by laws and regulations that "New" is judged depending on whether it corresponds to "medical difficult new medical technology that has never been implemented at the hospital excluding minor modification, and so forth,)" or technologies" not.

We showed our views that whether or not it corresponds to the "minor modification,and so forth" is judged on the degree of difference in "target disease", "expected result", "degree of difference in frequency and content of complications". And Emergency operation also corresponds to "minor modification, and so forth".

Surgeon's requirement

Skill of surgeon's should be matched to the standards established by academic societies If there is a standard the "highly difficult new medical technologies" the hospital is try to introduce.

If academic society have a specific training course or qualification for the "highly difficult new medical technologies", it is desirable that surgeon's have completed the training or qualified.

If there is no standard by academic societies, surgeon need Professional qualifications of basic area academic societies related to the "highly difficult new medical technologies".

Regarding new medical technology that is not widely spread in the public, the surgeon should have the experience of similar surgery to "highly difficult new medical technologies".

Guidance system

Meet the criteria on the way of "guidance system" based on the guidelines, etc. established by academic societies.

In addition, take one of the following measures:

1. Before introduction, as a medical team including surgeons etc., visit medical institutions that are experienced in providing the "highly difficult new medical technologies";

2. When the "highly difficult new medical technologies" is provided, those who are experienced in the technology are invited, and surgeons should be under the guidance.

Medical safety

Meet the criteria on the way of "Facility standards" and "implementation standards" based on the guidelines, etc. established by academic societies.

Take sufficient cooperation before performing surgery among staff concerned such as operating room, intensive care room, anesthesiologist, nursing department etc.

About 5 cases after introduction should report the description contents such as surgical record, medical record, etc. to the department in charge.

※ Regarding the specific number of cases requiring reporting, the department in charge of " highly difficult new medical technologies" should fully set up the contents of the offer from the department and set it in advance based on the opinion of the high-difficulty new medical technology evaluation committee.

Informed consent

A doctor who provides highly difficult medical technology or the attending doctor of the patient should explain to the patient under the presence of medical persons of different paramedical personal.

Explanation is done by the document, and the description content should include the following items:

1. Past surgical results in medical institutions related to the "highly difficult medical technology";

2. Provision of facilities and systems;

3. Professional qualifications of surgeons and previous surgical experience

4. Efficacy and safety (including comparison with alternative therapies).

special research group, Special Research Group on Evaluation and Improvement of Clinical Guidelines Concerning Introducing Process of Highly Difficult New Medical Technologies.

of domestic and foreign guidelines revealed in this survey for the purpose that the hospital can comply with laws and regulations and conduct the appropriate preliminary examination.

By introducing high-difficulty new medical technology based on these guidelines, Hospitals will comply with laws and regulations by introducing highdifficulty new medical technology based on these guidelines, and as a result, hospitals will be able to appropriately provide medical care with adequate difficulty to patients.

Also the special research group asked academic societies in each specialized field to actively disseminate information necessary for preliminary examination,"surgeon's requirement", "guidance system"," medical safety" "informed consent", with 
respect to individual high-difficulty new medical technologies. These efforts will contribute to the improvement of the quality of guidelines created by academic societies regarding "Highly Difficult New Medical Technology". Hopefully, Cooperative efforts by medical institutions, academic societies, and administrative agencies can contribute to reduce risk for patients receiving the technically demanding surgical procedures.

In conclusion, through domestic and overseas surveys, we found that there are no rules for how to introduce technically demanding operations at the governmental or ministerial levels. Therefore, new rules presupposing cooperation between administration, academia and medical institutions issued by the Japanese Ministry of Health, Labor and Welfare are a meaningful and novel approach.

\section{Acknowledgements}

This survey was supported by Ministry of Health, Labour and Welfare Sciences Research Grants, Special Research. The findings and conclusions of this article are solely the responsibility of the authors, and do not represent the official views of the Ministry of Health, Labour and Welfare.

We thank Prof. Jimmy So, Head \& Senior Consultant, Division of General Surgery; Prof. Lee Chuen Neng, Head, Department of Surgery, the National University of Singapore for interviewing. The authors thank Peipei Song Ph.D. for her devoted work in preparing the manuscript.

We thank all members from Special Research Group, ADACHI Hideo, ICHIKAWA Tomohiko,UETAKE Yuzaburo, SETO Yasuyuki, TOGASHI Junichi, HASEGAWA Kiyoshi, FUJII Tomoyuki, MATSUNO Akira, DOKI Yuuichirou, and NAKAMURA Masafumi.

\section{References}

1. Angst E, Hiatt J R, Gloor B, Reber H A ,Hines O J. Laparoscopic surgery for cancer: A systematic review and a way forward. J Am Coll Surg. 2010; 211:412-423 .

2. D'Amico TA. Long-term outcomes of thoracoscopic lobectomy. Thorac Surg Clin. 2008; 18:259-262.

3. The Japan Times. Gunma hospital reveals ninth death following laparoscopic surgery. https://www.japantimes. co.jp/news/2014/11/19/national/gunma-hospitalreveals-ninth-death-following-laparoscopic-surgery/\#. W4DqNegzaUk (accessed August 25, 2018)
4. Kaneko H, Otsuka Y, Kubota Y, Wakabayashi G. Evolution and revolution of laparoscopic liver resection in Japan. Ann Gastroenterol Surg. 2017; 1:33-43.

5. Government of Japan. Medical Care Act. http://www.japaneselawtranslation.go.jp/law/ detail/?id=2199\&vm=04\&re=01 (accessed August 25, 2018) (in Japanese)

6. Ministy of Health Labor and Welfare. About Medical Care by the newly introducing technically demanding operation Technologies and Unapproved Medical Products. https://www.mhlw.go.jp/stf/seisakunitsuite/ bunya/0000145803.html (accessed August 25, 2018) (in Japanese)

7. Chairman of The Japanese Association of Medical Sciences. Basic Approach to Medical safety assessed for the newly introducing process of the technically demanding operation. http://jams.med.or.jp/news/043. html (accessed August 25, 2018) (in Japanese)

8. Special Research group on evaluation and improvement of clinical practice guideline for newly introducing process of the technically demanding operation. Basic concept of newly introducing process of the technically demanding operation. http://jams.med.or.jp/news/043_1. $p d f$ (accessed August 25, 2018) (in Japanese)

9. Criteria for Inclusion in The National Guideline Clearinghouse (NGC) - Get Help, and give us Suggestions and Feedback. http://help.magicapp.org/knowledgebase/ articles/297449-criteria-for-inclusion-in-the-nationalguideline-c (accessed August 25, 2018)

10. NICE. Total hip replacement and resurfacing arthroplasty for end-stage arthritis of the hip. https://www.nice.org. uk/guidance/ta304/resources/total-hip-replacementand-resurfacing-arthroplasty-for-endstage-arthritisof-the-hip-review-of-technology-appraisal-guidance-2and-44-82602365977285 (accessed August 25, 2018)

11. Lyman, GH, Somerfield MR, Bosserman LD, Perkins CL, Weaver DL, Giuliano AE. Sentinel lymph node biopsy for patients with early-stage breast cancer. American Society of Clinical Oncology Clinical Practice Guideline Update. J Clin Oncol. 2017; 35:561-564.

12. NICE. Laparoscopic repair of abdominal aortic aneurysm. https://www.nice.org.uk/guidance/ipg229/ resources/laparoscopic-repair-of-abdominal-aorticaneurysm-pdf-1899865283911621 (accessed August 25, 2018).

13. NICE. Laparoscopic retroperitoneal lymph node dissection for testicular cancer. https://www.nice.org.uk/ guidance/ipg158/resources/laparoscopic-retroperitoneallymph-node-dissection-for-testicular-cancer-pdf (accessed August 25, 2018).

14. Herron DM, Marohn M, SAGES-MIRA Robotic Surgery Consensus Group. A consensus document on robotic surgery. Surg Endosc. 2008; 22:313-325.

(Received September 17, 2018; Revised December 13, 2018; Accepted December 20, 2018) 